\title{
A desalambrar. Agricultura urbana, huertos comunitarios y regulación urbanística
}

\author{
Sweeping away barriers. Urban agriculture, \\ community gardens and urban regulation
}

\author{
Nerea Morán Alonso* y José Luis Fernández de Casadevante** \\ Fecha de recepción: 24-VI-2013 - Fecha de aceptación: 13-I-2014 \\ Hábitat y Sociedad (ISSN 2173-125X), n. ${ }^{\circ}$ 7, noviembre de 2014, pp. 31-52.
}

\section{Summary}

Urban agriculture is beginning to gain importance in Spain. Nevertheless there are several difficulties for its recognition in municipal regulation, especially regarding community gardens. This perpetuates the insecurity and precariousness of these projects.

Comparative analysis of urban agriculture regulation (as defined in law, urban planning, zoning codes, and other legal instruments) in western cities, has allowed us to identify operational tools and processes that work in other countries and can be adapted to Spanish urban planning. This requires a wider municipal commitment, and recognition of the potential of urban agriculture. Tentative progress are not up to par with another countries regulating framework development.

\section{Key words}

Urban agriculture, community garden, urban codes, urban planning

\section{Resumen}

Los huertos urbanos empiezan a adquirir importancia en el Estado español en los últimos años. Sin embargo, no se han superado las dificultades para su reconocimiento legal, especialmente en el caso de los huertos comunitarios, perpetuándose la inseguridad y precariedad de las iniciativas.

El análisis comparativo de la regulación de la agricultura urbana (definida en leyes, planeamiento y otros instrumentos) en ciudades occidentales, nos permite identificar los procesos y herramientas operativas que han sido útiles en otros países y que podrían adaptarse a las peculiaridades de nuestro planeamiento. Para ello es necesario un compromiso municipal más fuerte y un reconocimiento de las múltiples potencialidades de la agricultura urbana. Los tímidos avances que se han realizado por el momento no se encuentran a la altura del marco normativo desarrollado en otros países.

\section{Palabras clave}

Agricultura urbana, huertos comunitarios, normativas municipales, planificación urbanística

\footnotetext{
* Arquitecta urbanista, Personal Investigador, Grupo de investigación en Urbanismo, Arquitectura y Sostenibilidad (GIAU+S, UPM).

** Sociólogo, Miembro de Garua S. Coop. Mad. y responsable de Huertos Urbanos de la Federación Regional de Asociaciones Vecinales de Madrid-FRAVM
} 


\section{Introducción}

Desafortunados aquellos a quienes les toca vivir tiempos interesantes. Proverbio Chino.

La agricultura y la ciudad en Occidente han sostenido una relación simbiótica que se quiebra con la llegada de la revolución industrial, que supone la expansión acelerada y desordenada de la ciudad a expensas de un espacio agrario considerado prescindible. La agricultura, desterrada de la ciudad o arrinconada en sus márgenes, reaparecía de forma recurrente durante periodos de crisis: recesiones económicas, conflictos bélicos, abandono institucional de barrios... (Morán, 2009; Casadevante, 2012), de modo que los huertos urbanos adquieren relevancia pública durante tiempos de escasez, en los que se establecen medidas especiales para su fomento.

La historia de la agricultura urbana (AU en adelante) se encuentra estrechamente ligada a los procesos de industrialización. En Europa los países que realizaron antes la transición hacia economías industrializadas coinciden con aquellos que disponen de normativas que regulan la AU desde hace más de un siglo, mientras los países del arco mediterráneo, con una industrialización y éxodos rurales más tardíos, se encuentran actualmente ante la emergencia de una AU con difícil encaje en sus disciplinas urbanísticas. Esta diferencia se ilustra en la Figura 1, que muestra los países representados en la Federación Internacional de Jardines Familiares ${ }^{1}$ (Office International du Coin de Terre et des Jardins Familiaux), agrupación de asociaciones europeas.

Figura 1. En verde los países federados Fuente: Office International du Coin de Terre et des Jardins Familiaux.

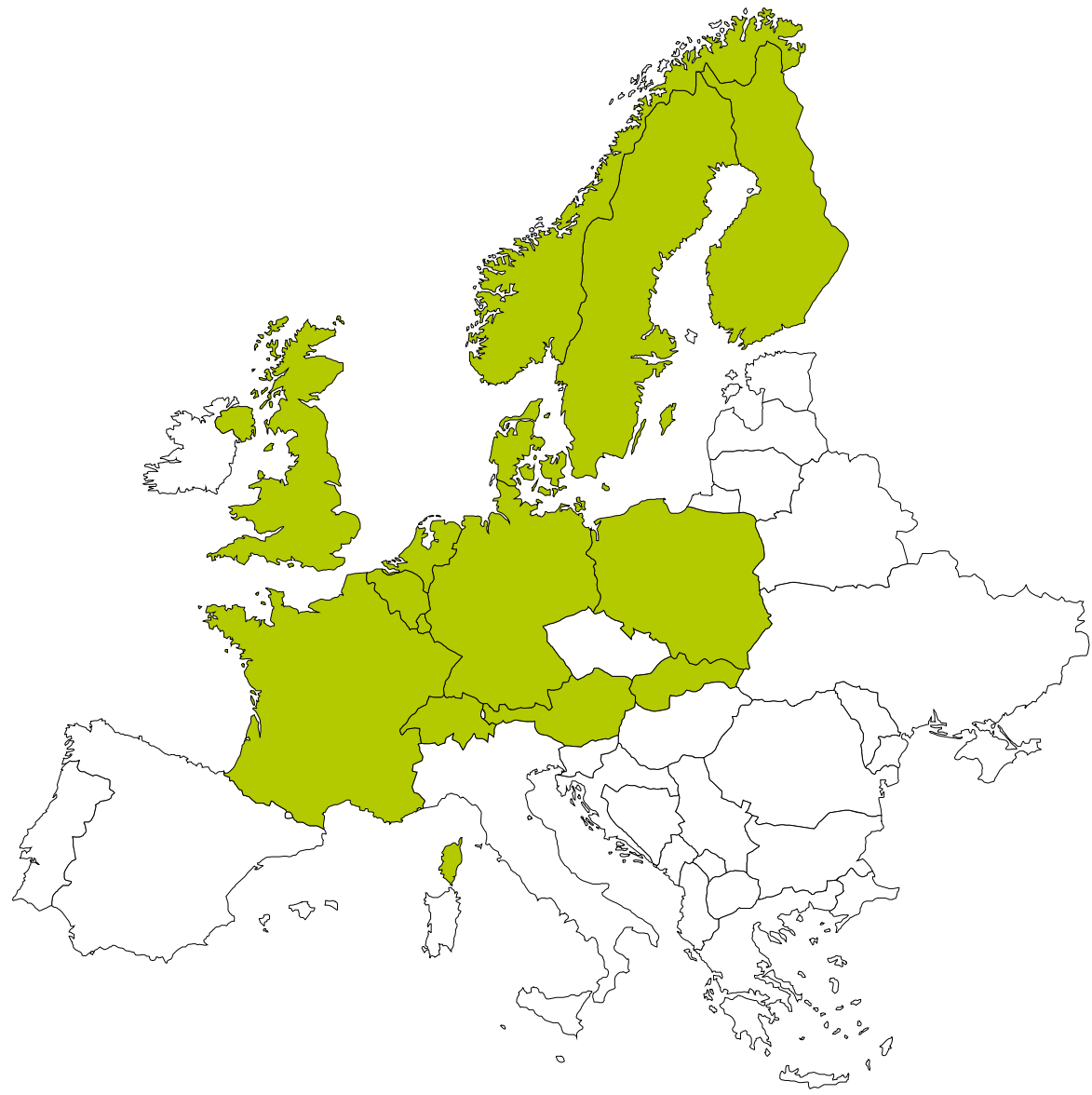


En el ámbito internacional la AU es un tema de estudio reconocido, en Norteamérica hay equipos especializados en las universidades desde los años setenta (Maryland, Pennsylvania, Cornell-New York, MITPhiladelpia...). En Europa las diferencias regionales provocan fuertes contrastes entre países con mucha tradición en su estudio (Alemania, Inglaterra, Suecia...) y otros donde éste es un campo de reflexión reciente. A nivel comunitario el programa de transferencia de ciencia y tecnología COST, ${ }^{2}$ está financiando una red de investigación sobre allotments y huertos comunitarios, en la que participan 28 países, con el objetivo de analizar el papel de estos espacios dentro del modelo urbano, su situación normativa, y sus virtudes ecológicas y sociales, estudiando casos nacionales para caracterizar las peculiaridades, procesos, problemas y posibilidades de la AU en la Unión Europea.

En nuestra geografía la AU ha proliferado durante los últimos años, una expansión tanto en términos cuantitativos, con centenares de nuevas iniciativas pendientes de la realización de un censo exhaustivo, como cualitativos, expresada en una creciente hortodiversidad ${ }^{3}$ (Fdez. Casadevante y Morán, 2012). Además de este impulso dado por la sociedad civil, la AU ha comenzado a convertirse en un campo de creciente interés académico y profesional para distintas disciplinas ${ }^{4}$ (antropología, sociología, biología, educación, trabajo social, urbanismo, arte...), lo que se evidencia en la celebración en 2011 del I Congreso Estatal de Agricultura Urbana Ecológica en Elche, la multiplicación de seminarios, jornadas, monográficos de revistas o los trabajos académicos realizados en Madrid (Verdaguer y Vázquez, 2010), Cataluña (Arosamena, 2012) o Andalucía (Puente, 2012).

La AU se ha revelado como una actividad que provoca beneficios sociales (ocio, participación, creación de comunidad, identidad...) y ambientales (aumento de zonas verdes, educación ambiental, compostaje, biodiversidad urbana...), por lo que debe ser considerada como un elemento clave para cualquier estrategia de regeneración urbana en clave de sostenibilidad y justicia social. Una vez dicho esto, asistimos a las enormes dificultades que encuentran los proyectos de AU para consolidarse dentro del marco normativo y las políticas públicas de nuestras ciudades (falta de regulación, conflicto con usos permitidos por el planeamiento, desmantelamiento de iniciativas...). ¿Cómo abordamos esta contradicción? ¿De qué manera se pueden salvar las desconfianzas mutuas entre la sociedad civil y las Administraciones Públicas a la hora de promover la AU? Un aporte para diluir los miedos recíprocos pasa por estudiar y analizar cómo se han solventado estas tensiones en ciudades donde la incorporación de la AU en el planeamiento urbano está consolidada.

\section{Metodología}

Si quieres conocer algo, trata de cambiarlo. K. Lewin.

El objetivo de este texto es analizar una serie de experiencias de AU en distintas ciudades occidentales, para identificar herramientas normativas que puedan servir de inspiración a la hora de realizar propuestas adaptadas a nuestras ciudades. Para ello se han realizado las siguientes tareas:
1 Esta organización internacional cuenta con 14 asociaciones de diferentes países europeos, y actúa como grupo de presión en el Parlamento Europeo para la conservación de los huertos urbanos. Ver: http://www.jardins-familiaux.org/

2 Ver página del proyecto: http://www. cost.eu/domains_actions/tud/Actions/ TD1106

3 Los espacios, los formatos, las imágenes que asociamos a la agricultura urbana son mucho más plurales y diversos que la parcela de tierra con surcos. Apareciendo huertos de ocio o familiares, comunitarios, escolares, terapéuticos, terrazas, azoteas...

4 Compilación de trabajos académicos realizados en colaboración con la Red de Huertos Comunitarios de Madrid: http:/ / portal.ucm.es/web/agroecologia/trabajos-academicos 
- Descripción del desarrollo de huertos de ocio y comunitarios en función del contexto social y político.

- Identificación de las condiciones de uso que establecen los documentos legales y normativos: definición de la AU; usos del suelo y seguridad de permanencia; condiciones de la actividad.

- Análisis de resultados: conclusiones y recomendaciones para el caso español.

Se ha procedido a una exhaustiva revisión bibliográfica, de textos legislativos (escala estatal), documentos de planeamiento urbano y normativa de usos del suelo (escala municipal o de distrito), y otras herramientas como contratos de cesión o reglamentos internos (aplicados a espacios concretos, sin competencias para cambiar los usos de suelo legalmente aprobados).

La selección de las ciudades de estudio se realiza siguiendo los siguientes criterios: tradición histórica en la regulación de la AU, diversidad de tipologías de huertos y cambios recientes en la regulación. Con estas premisas se han escogido dos casos europeos (Londres y Berlín) y uno del norte de América (San Francisco), y se han comparado sus desarrollos legislativos y normativos con los modestos avances e iniciativas que se han ido impulsando en nuestra geografía. En los casos de Berlín y Londres el análisis parte del realizado en textos previos (Morán, 2009; Morán y Aja, 2011), revisados y ampliados a la luz de las novedades normativas posteriores a 2011.

\section{Casos}

Una cosa no es justa por el hecho de ser ley. Debe ser ley por el hecho de ser justa. Montesquieu.

\subsection{San Francisco, California, Estados Unidos}

\subsubsection{Contexto}

En Estados Unidos el origen de la AU está ligado a la lucha contra la pobreza, como la crisis de finales del siglo XIX, donde nacería la Vacant-Lot Cultivation Asociation, que organiza el cultivo de espacios libres en las ciudades por parte de personas desempleadas. Un movimiento donde se entrecruzaban la filantropía, los apoyos de las autoridades locales (que cedían temporalmente terrenos y facilitaban la comercialización de los productos) y los esfuerzos cooperativos de apoyo mutuo de las organizaciones obreras. Este movimiento tendría influencia durante el principio de siglo, hasta la Gran Depresión, en la que obtiene un renovado protagonismo; en 1934 se llegan a censar 1.820 .633 iniciativas (Lawson, 2005).

Además de las oleadas cíclicas de programas de emergencia, que se difuminan cuando la situación económica mejora, durante las dos guerras mundiales también se lanzaron ambiciosos programas federales que sitúan la AU como elemento de movilización patriótica en la retaguardia, así como recurso que facilitaba la producción y el consumo local, reservando el transporte para el envío de armas, munición y comida a los países aliados (Morán, 2009). 
En los años setenta en un contexto de crisis urbana y fiscal surgen los primeros huertos comunitarios (community gardens) en EE.UU. En ellos confluyen las luchas urbanas por la justicia social, emprendidas por las organizaciones barriales durante las décadas anteriores, y las movilizaciones por cuestiones ambientales de los incipientes colectivos ecologistas (Fernández Casadevante y Morán, 2012). La recuperación de espacios abandonados y degradados para transformarlos en huertos se convierte en objetivo y herramienta del activismo social. Por primera vez en la historia del país la sociedad civil protagoniza, demanda y articula de forma participativa proyectos de AU. Desde entonces el movimiento se ha ido coordinando a nivel nacional y ha sido el principal impulsor de la diversificación y modernización de programas, además de realizar una labor de incidencia política para el avance de la legislación y normativas.

Las actuaciones más recientes además de cuestiones ambientales y climáticas abordan el problema de la expansión de Food Deserts o desiertos alimentarios, que evidencian las crecientes dificultades de acceso a alimentos frescos que surgen del cruce de modelos de ciudad poco compactos, del abandono de las políticas públicas que promueven un reequilibrio en los barrios donde viven los colectivos sociales más vulnerables económicamente y de la huida de muchos comercios de proximidad de vecindarios que además padecen una fuerte segregación étnica. ${ }^{5}$

Los principales agentes de la sociedad civil que participan en la AU son los grupos comunitarios, productores y consumidores, ONG y colectivos de carácter educativo o de emergencia alimentaria, así como organizaciones de incidencia política, o fundaciones como las Land Trusts. ${ }^{6}$

San Francisco dispone de un programa de huertos municipales desde 1970, a partir de 1981 los huertos adquieren un perfil más activista con la conformación de la San Francisco Urban Gardeners League (SFUGL), actualmente una de las mayores organizaciones del país, centrada en intervenir en barrios de bajos ingresos manejando la AU como herramienta de inserción laboral, llegando a emplear a 200 personas en 2002 (Lawson, 2005). La San Francisco Urban Agriculture Alliance (SFUAA) agrupa 55 organizaciones, y trabaja para la promoción de la AU mediante proyectos, apoyo e incidencia política.

\subsubsection{Regulación de huertos comunitarios}

La distinción entre huertos tradicionales y comunitarios que realizaremos en Europa no puede trasladarse a EE.UU., donde bajo la denominación de community garden se agrupan variados formatos de huertos asociativos.

Analizando el estudio de 16 ciudades estadounidenses realizado por Goldstein et al. (2010) se puede observar que aunque existen programas de huertos comunitarios desde los años setenta, ${ }^{7}$ en la última década se está desarrollando legislación que favorece la AU, eliminando barreras administrativas al cultivo y a la venta. ${ }^{8}$ Distintas ciudades han revisado sus ordenanzas urbanas para incorporar y regular estos usos, definiendo categorías específicas de Urban Agriculture (Philadelphia, 2012; San Francisco, 2012; Kansas, 2010), Community Garden (Boston, 2010), Neighborhood Agriculture (Chicago, 2011), Urban Garden District (Cleveland, 2007), Urban Farm (Seattle, 2010)... En general, se permiten construcciones ligeras, y se regula la cría de ani-
$5 \quad$ El propio Gobierno de EE. UU. estima que 13,6 millones de personas, generalmente pertenecientes a población negra y otras minorías, tienen un acceso difícil a un supermercado o gran tienda de comestibles ya que viven a una distancia superior a 1,6 Km. Ver la página del Departamento de Agricultura de EE.UU. sobre los Food Deserts: http://www.ers.usda.gov/ Data/FoodDesert/

6 Organizaciones sin ánimo de lucro que adquieren terrenos y los ceden a grupos comunitarios, encargándose de la gestión de impuestos, seguros y responsabilidad ante la Administración

$7 \quad$ P-Patch Community Garden Program de Seattle (1973), Community Garden Program de Portland (1975), Green Thumb de Nueva York (1978). (Goldstein et al, 2010)

8 Georgia Right to Grow Act (2012), Massachusetts Land Use Partnership Act (en debate), Illinois Local Food, Farms and Jobs Act (2009), Maryland UA Tax Credit Act (2010), Georgia Food Freedom Act (2012), California Homemade Food Act (2012). 
Cuadro 1. Regulación según la ordenanza, San Francisco. Fuente: elaboración propia a partir de Goldstein (2011). males, sobre todo abejas y aves de corral. Un aspecto importante que no aparece en todas las ordenanzas es la seguridad de la actividad, en Portland (2012) y Seattle (2010) es obligatorio un análisis del suelo para detectar metales pesados y otros contaminantes; Seattle además establece condiciones sobre la calidad del agua y los impactos de la actividad (erosión, sedimentación, ruido, olores, uso de pesticidas y fertilizantes, maquinaria...).

Nos centraremos en el caso de San Francisco, que ha aprobado en 2012 y 2013 nuevas leyes y ordenanzas.

Legislación. En California acaba de aprobarse (septiembre de 2013) la ley UA Incentive Zones Act (Estado de California, 2013), con el apoyo de diversas organizaciones de desarrollo comunitario, agrupaciones profesionales (American Planning Association) y Gobiernos locales, como Berkeley o Los Angeles, ${ }^{9}$ que la consideran un impulso al fomento de la AU, la economía y la alimentación locales, y la recuperación de áreas abandonadas dentro de los límites urbanos. Esta ley permite a las ciudades y condados delimitar dentro de sus áreas urbanas "ámbitos de fomento de AU", que se preservarán de la urbanización y en los que se fomentará el uso agrícola (hortícola, ganado, apicultura, aves, espacios educativos, pero no silvicultura). El municipio establecerá contratos voluntarios de al menos cinco años con los propietarios, por los que se obliga al uso agrícola, comercial o no, en terrenos de no más de tres acres (1,2 ha). Los terrenos sujetos a estos contratos contarán con ventajas fiscales, al valorarse como agrícolas de cara a fijar las tasas que los propietarios deben pagar.

\begin{tabular}{|c|c|}
\hline DEFINICIÓN & $\begin{array}{l}\text { Cultivo de plantas y cría de animales, que se puede realizar en jardines privados, com unitarios, } \\
\text { comerciales, demostrativos, o institucionales: colegios, lugares de trabajo, cubiertas verdes. } \\
\text { Comercial o no. }\end{array}$ \\
\hline \multirow{5}{*}{$\begin{array}{l}\text { USOS DEL } \\
\text { SUELO }\end{array}$} & CATEGORÍA ESPECÍFICA: Urban Agriculture. Subcategorías: \\
\hline & AU de barrio (CG, CSA, market gardens y UF). Menos de un acre = 0,4 ha. \\
\hline & AU de gran escala; \\
\hline & Conservación de agua (parcelas de más de 1000 pies $^{2}=93 \mathrm{~m}^{2}$ ). \\
\hline & $\begin{array}{l}\text { USO PERMITIDO EN SUELO URBANO: Suelo residencial (unifamiliar o multifamiliar), comercial o } \\
\text { industrial. La de gran escala debe obtener permiso. }\end{array}$ \\
\hline \multirow{6}{*}{$\begin{array}{l}\text { CONDICIONES } \\
\text { ACTIVIDAD }\end{array}$} & CONSTRUCCIONES: Requerimientos estéticos, condiciones de materiales de vallado. \\
\hline & CRÍA DE ANIMALES: No se especifica \\
\hline & VENTADE LA PRODUCCIÓN: No se permite en dis tritos residenciales \\
\hline & ACTIVIDADES COMPATIBLES \\
\hline & $\begin{array}{l}\text { Compostaje: se establecen condiciones de distancia a linderos }(3 \text { pies }=0,9 \mathrm{~m}) \text { y de } \\
\text { localización del uso en la parcela. }\end{array}$ \\
\hline & Uso de maquinaria: No se permite en distritos residenciales \\
\hline
\end{tabular}

9 Como se puede comprobar en los análisis de la ley recogidos en California Legislative Information: http:/ / leginfo.legislature.ca.gov/faces/billNavClient.xhtml
Ordenanzas Urbanas. La UA Zoning Ordinance (City and Council of San Francisco, 2011), analizada por Goldstein et al. (2011), se redacta con el fin de establecer una categoría específica de uso del suelo para AU. Fue ampliamente apoyada por agentes locales, aunque la SFUAA hizo algunas recomendaciones relativas al vallado y las dificultades económicas que podían suponer para grupos comunitarios tener que utilizar los materiales exigidos en la norma. 
Un resumen de las determinaciones normativas según esta ordenanza se puede ver en el Cuadro 1 .

Un año después se aprueba la ordenanza UA Ordinance (City and Council of San Francisco, 2012), que no afecta a los usos del suelo, sino al papel del Gobierno local en el fomento y coordinación de actividades de AU, para lo que establece el Urban Agriculture Program. Once departamentos y agencias públicas financian o apoyan actividades de AU pero hasta este programa sin coordinación y sin personal encargado. La ordenanza destaca los beneficios recreativos, económicos, alimentarios, ecológicos, comunitarios y sociales de la $\mathrm{AU}$, reconoce la necesidad de más espacios de cultivo reclamada por los ciudadanos y considera que hay capacidad de proveerlos mediante suelo público. También se refiere a la necesidad de desarrollar infraestructuras adecuadas (agua, canales de riego, instalaciones de procesado y venta de alimentos, educativas).

Los objetivos del programa son la coordinación interdepartamental, la promoción de políticas y estrategias, el establecimiento de acuerdos y alianzas con grupos y organizaciones comunitarias, la recogida de datos y la publicación de información, la coordinación entre agencias públicas y agricultores urbanos para destinar los excedentes del cultivo a programas sociales y el estudio de las posibilidades de creación de empleo. El ente encargado de su impulso es el Department of Parks $\mathcal{E}^{\circ}$ Recreation.

Por el momento ha realizado varios avances en estos objetivos, eliminando barreras burocráticas mediante la creación de una oficina central que coordina a las distintas agencias municipales. También ha evaluado la capacidad de desarrollar proyectos de AU en suelos y en cubiertas de edificios públicos, instalando dos granjas; ha recogido datos para monitorizar el avance de la $\mathrm{AU}$; ha puesto en marcha incentivos para activar suelos vacantes, ofrece asistencia y recursos en la formación de nuevos huertos comunitarios y ha incorporado la AU en programas de formación y empleo.

La ordenanza establecía la obligación de redactar un plan estratégico que se ha publicado recientemente, el Urban Agriculture Strategic Plan (City of San Francisco, 2013).

\subsection{Berlín, Alemania}

\subsubsection{Contexto huertos tradicionales}

La historia de los kleingarten se remonta al s XIX, de la mano de las medidas impulsadas por el movimiento higienista para mejorar las condiciones de habitabilidad de la ciudad industrial. Los huertos surgieron como una evolución de los espacios de juego infantiles al aire libre impulsados por el Dr. Schreber. Desde sus orígenes fueron gestionados por asociaciones que tenían un fuerte peso político y un notable arraigo ciudadano, sobreviviendo a las disputas obreras, la infiltración del nazismo y la reconstrucción después de la segunda guerra mundial. Tras la unificación, las movilizaciones de los hortelanos consiguen asegurar la permanencia de los huertos en el planeamiento urbano, convirtiéndose en entidades con participación en foros y espacios de deliberación política.

En Berlín hay 74.500 kleingarten, que ocupan 3.000 ha, de las que $3 / 4$ son terrenos propiedad del Estado. El departamento municipal encargado es el de Planificación y Medio Ambiente (Senatsverwaltung 
für Stadtentwicklung und Umwelt), sus competencias están distribuidas por distritos. Este departamento calcula en 500 euros el coste anual de una parcela, incluyendo el alquiler, la cuota de la asociación, los impuestos y el consumo de agua, alcantarillado y electricidad.

Los contratos se realizan entre el distrito, que proporciona el terreno y las infraestructuras (agua, accesibilidad, higiene), y una asociación de hortelanos (Kleingartenvereine, Schrebengartenvereine), que arrienda los terrenos, los divide en parcelas individuales, recauda las rentas, organiza los cambios de adjudicatarios y mantiene las áreas comunes.

En Berlín existen unas 800 asociaciones locales de hortelanos, agrupadas en 12 asociaciones de distrito cuya función es la intermediación con la Administración. Las asociaciones se reúnen en la coordinadora estatal Landesverband Berlin der Gartenfreunde, que analiza las políticas, asesora sobre las reglas generales de diseño, alquiler y gestión, y realiza actividades de difusión, como la edición de un periódico. Esta organización representa a unos 70.000 hortelanos, que celebran elecciones cada cuatro años para elegir a la Junta Directiva. Las organizaciones estatales se federan a su vez en la Bundesverband Deutscher Gartenfreunde (Unión Federal de Huertos Urbanos), que junto a las federaciones de Francia y Polonia fue fundadora de Office International du Coin de Terre et des Jardins Familiaux en 1921 (Morán y Hernández, 2011).

\subsubsection{Regulación de huertos tradicionales}

Legislación. Alemania cuenta con legislación específica que regula los kleingarten desde principios del siglo XX. La ley federal vigente es la Bundeskleingartengesetz (1983, modificada en 2006), complementada con disposiciones administrativas del Estado de Berlín que afectan a la indemnización por fin de uso (Verwaltungsvorschriften über Kündigungsentschädigung auf Kleingartenland, 2003), a los kleingarten en terrenos públicos (Verwaltungsvorschriften über Dauerkleingärten und Kleingärten auf landeseigenen Grundstücken, 2009), y a las asociaciones, que deben ser de carácter no lucrativo y estar incluidas en el Registro de Asociaciones (Verwaltungsvorschriften über die Anerkennung und Überwachung der kleingärtnerischen Gemeinnützigkeit, 2009).

Regulación urbanística. Planeamiento y usos del suelo. Berlín introducía recientemente la noción de paisaje productivo en un documento estratégico sobre la gestión del medio ambiente urbano, planteando que la municipalidad debería proporcionar espacios verdes que impulsen estilos de vida ecológicos en la población, contemplando los huertos tradicionales, los comunitarios y otras experiencias con participación ciudadana en el diseño (Senatsverwaltung für Stadtentwicklung und Umwelt, Berlin, 2012).

$\mathrm{Al}$ margen de las recomendaciones estratégicas, el único modo de asegurar la permanencia de los huertos es su reconocimiento en el planeamiento. En Alemania el Flächennutzungs-planung Berlin-FNP (1994) es el planeamiento marco general, y el Bebauungsplan (B-Plan), el planeamiento vinculante de desarrollo para áreas concretas dentro de la ciudad, obligatorio en sus determinaciones sobre usos del suelo. El Código federal de Construcción (Baugesetzbuch) en su Capítulo 1: Ley General de Ordenación Urbana, Sección tercera: Plan vinculante de desarrollo (zonificación), Punto 9: Contenido del Plan de Desarrollo, define entre las determinaciones que puede establecer el B-Plan los "espacios verdes públicos y privados, como parques, huertos (dauerkleingarten), espacios deportivos, áreas de acampada y de baño, cementerios..." (BGBI, 2004). 
Un resumen de las determinaciones normativas se puede ver en el Cuadro 2.

\begin{tabular}{|c|c|}
\hline DEFINICIÓN & $\begin{array}{l}\text { Kleingarten: jardín de no más de } 400 \mathrm{~m}^{2} \text { para autoabastecimiento y recreación, situado en un } \\
\text { espacio en el que se agrupan parcelas individuales con instalaciones colectivas (caminos, áreas } \\
\text { de juego, salas de reunión). Al menos } 2 / 3 \text { de la parcela para cultivo de hortalizas. LEY }\end{array}$ \\
\hline $\begin{array}{l}\text { USOS DEL } \\
\text { SUELO }\end{array}$ & CATEGORÍA ESPECÍFICA: Kleingarten permanentes y temporales (B-plan) \\
\hline \multirow[b]{5}{*}{$\begin{array}{l}\text { CONDICIONES } \\
\text { ACTIVIDAD }\end{array}$} & $\begin{array}{l}\text { CONSTRUCCIONES: Casa de verano, área máxima de } 24 \mathrm{~m}^{2} \text {. No se permite su uso permanente } \\
\text { como alojamiento. (Ley Federal) } \\
\text { Berlín: invernaderos, sistemas fotovoltaicos, estanques o juegos infantiles. (Ley Estatal) }\end{array}$ \\
\hline & $\begin{array}{l}\text { CRÍA DE ANIMALES: No es tá permitido. (Ley Federal) } \\
\text { Berlín: se permiten abejas si el fin no es comercial. (Ley Estatal) }\end{array}$ \\
\hline & VENTADE LA PRODUCCIÓN: No se permite \\
\hline & $\begin{array}{l}\text { ALQUILER: No puede exceder cuatro veces el arriendo agrícola (terrenos para el cultivo } \\
\text { comercial de frutas o verduras situados en el área, y si no los hay, en una zona equiparable). }\end{array}$ \\
\hline & $\begin{array}{l}\text { FIN DEL CONTRATO E INDEMNIZACIÓN: Supuestos admisibles: reorganización interna de los } \\
\text { kleingarten; que el propietario desee destinar el suelo a otro uso permitido por el planeamiento; o } \\
\text { que el planeamiento de desarrollo B-Plan reclame el suelo para desarrollar el uso que le } \\
\text { asigna. (Ley Federal) } \\
\text { La ley establece los periodos en los que se debe avisar de la finalización del contrato, la } \\
\text { capacidad de expropiar si no se llega a un acuerdo y el pago de compensaciones (según cultivos } \\
\text { e instalaciones que se han realizado), además recomienda al municipio proporcionar nuevos } \\
\text { terrenos adecuados. (Ley Federal) } \\
\text { Berlín: Se establecen valores de indem nización de los distintos elementos, construcciones y } \\
\text { cultivos. Ley Estatal, } 2003\end{array}$ \\
\hline
\end{tabular}

En 2004 el Estado de Berlín realiza un Kleingartenentwicklungsplan ${ }^{10}$ (Plan de Desarrollo de los kleingarten), que ha sido actualizado en 2010; incluye un inventario de emplazamientos y establece su grado de protección: los asegurados permanentemente son los reconocidos por el planeamiento (el 82\%) y los que han conseguido una ampliación en su protección en el FNP hasta 2020 o 2014 (19 espacios). Como ejemplo, el distrito de Charlottenburg en la Figura 2.

\subsubsection{Contexto de los huertos comunitarios}

El origen de los huertos comunitarios en Berlín se puede enmarcar en las protestas y propuestas de los nuevos movimientos sociales de los ochenta, movimientos okupa y ecologista que desarrollaron proyectos de autogestión y también de defensa del verde urbano. Los primeros huertos comunitarios surgen en conflicto con las autoridades locales, mediante la ocupación de espacios, en paralelo a la presión y negociación. Un ejemplo es el Kinderbauernhof Mauerplatz, en el distrito de Kreuzberg, ocupado entre 1981 y 2001, y que finalmente consigue un contrato de cinco años con el distrito.

En la actualidad, debido a la falta de presupuesto municipal, la Administración apoya este tipo de proyectos en suelos públicos y también privados, en los que la paralización del desarrollo inmobiliario hace que los propietarios sean más proclives a permitirlos. El futuro de los huertos comunitarios no está asegurado, según Rosol son "entendidos
Cuadro 2. Regulación de los huertos tradicionales según legislación y planeamiento, Berlín. Fuente: elaboración propia.

10 Ver http://www.stadtentwicklung.berlin.de/umwelt/stadtgruen/kleingaerten/ de/kleingartenentwicklungsplan/index. shtml 
principalmente como una medida provisional o una segunda opción en temporadas de poco desarrollo inmobiliario" (Rosol, 2010, p. 558); la autora describe el proceso actual como muestra de dos tendencias de la neoliberalización urbana: la falta de inversión pública y la responsabilización de las comunidades en la provisión de equipamientos y en el mantenimiento de sus barrios, frente a la responsabilidad del gobierno local (ob. cit.).

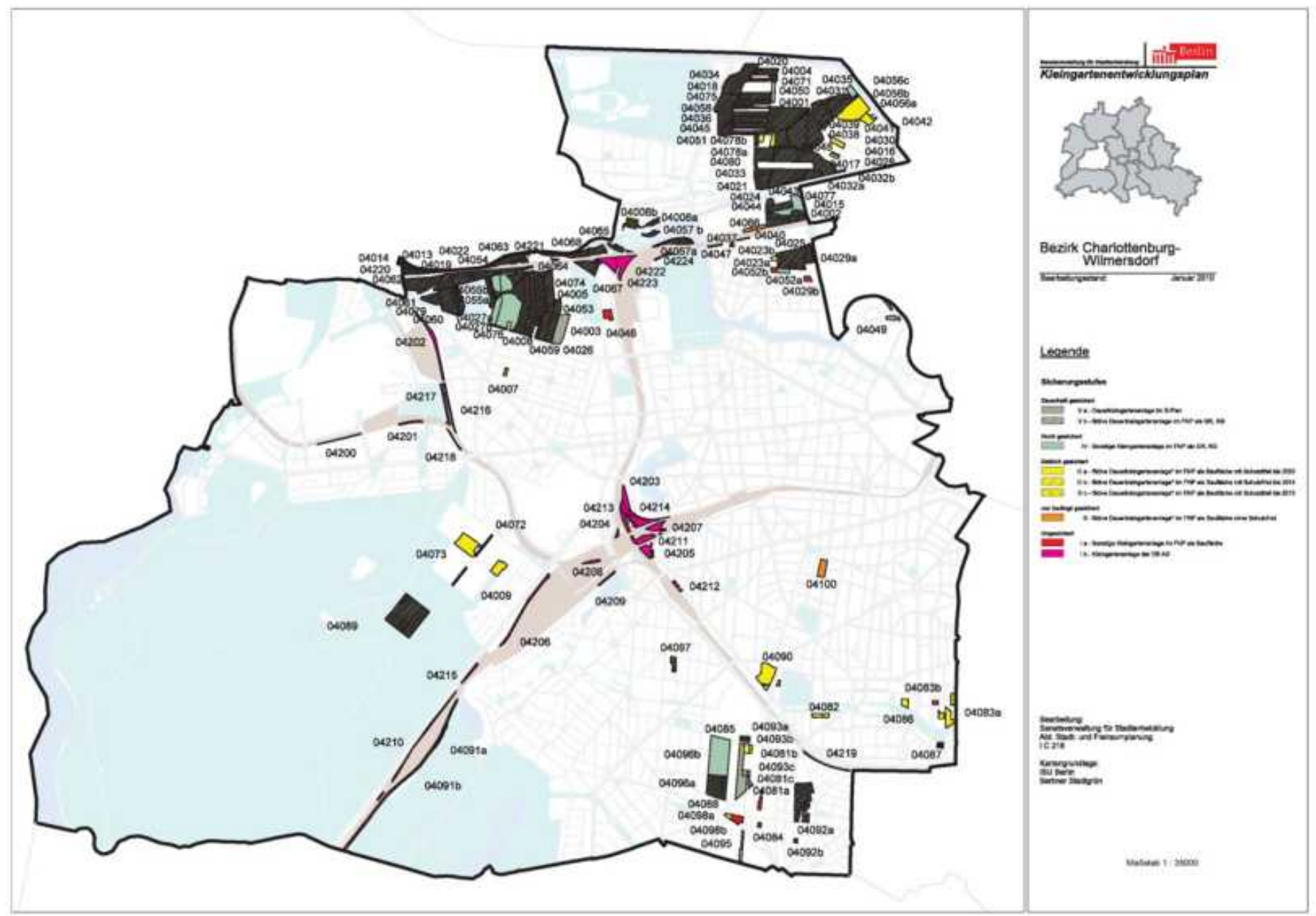

Figura 2. Distrito de Charlottenburg-Wilmersdorf. Inventario de kleingarten y grado de protección. Verde oscuro: protección permanente en B-Plan, y protección teórica permanente en FNP. Verde claro: seguridad alta. Amarillo: ampliación de protección en FNP hasta 2010, 2014, 2020. Naranja: seguridad limitada. Rosa y rojo: sin garantía de permanencia. Fuente: Estado de Berlín, 2010.

11 http://www.tempelhoferfreiheit.de/ en/get-involved/pioneer-projects/allmende-kontor/

12 Base de datos de la plataforma on-line stadtacker.net
Un ejemplo de esta nueva postura municipal sería el huerto comunitario desarrollado como iniciativa ciudadana en el aeropuerto de Tempelhof. Tras el cierre del aeropuerto en 2008, miles de activistas lo ocupan en 2009 para prevenir su privatización, en 2010 la municipalidad lo abre al público como parque en espera de su desarrollo residencial y recreativo. Ante los problemas presupuestarios para equiparlo el municipio lo abre a iniciativas ciudadanas, que llama "pequeños proyectos pioneros". Entre ellos el huerto comunitario sobre bancales elevados gestionado por Allmende-Kontor (oficina de espacios comunitarios), que es una iniciativa de coordinación y fomento de proyectos de $\mathrm{AU}$, desde el enfoque del desarrollo urbano, la soberanía alimentaria y los comunes, que se inicia en 2010. El huerto es también espacio educativo y de coordinación entre proyectos existentes, ofreciendo asesoría en cultivos, en búsqueda de financiación y en diseño de programas educativos; desarrolla un centro de recursos para compartir materiales, y ha comenzado un banco de semillas para intercambio. ${ }^{11}$

En la actualidad existen 85 iniciativas sociales de AU en Berlín y nueve más en proyecto, ${ }^{12}$ de diversos tipos: interculturales, vecinales, 
granjas urbanas, itinerantes, comerciales, educativos, juveniles, en cubiertas, de guerrilla... que no cuentan con un marco común de regulación o procedimientos. Sus fines son sociales, ecológicos, económicos y políticos y, a diferencia de los norteamericanos, no tienen un propósito productivo, sino esencialmente demostrativo. Gestionados por asociaciones formales o grupos comunitarios, obtienen la financiación de distintas fuentes: donaciones y cuotas, financiación pública (creación y en algunos casos también mantenimiento). No están agrupados en una red, aunque existen diversas asociaciones e iniciativas transversales, como Berlin is buzzing!, ${ }^{13}$ dedicada a la apicultura, Interkultur gartens, ${ }^{14}$ de inclusión social, RoofTUBgarden que promueve el uso de azoteas comestibles o Social Seeds, ${ }^{15}$ para la promoción de variedades locales y el intercambio de semillas.

\subsubsection{Regulación de los huertos comunitarios}

Los huertos comunitarios no cuentan con un marco regulador similar al de los tradicionales kleingarten, por lo que su situación es bastante más precaria. Las cesiones temporales son la principal fórmula utilizada en la actualidad, en ellas las autoridades locales pasan a jugar un papel de facilitadores, dando permisos, cediendo sin coste o alquilando el suelo, cofinanciando los proyectos o buscando programas externos de financiación, y arbitrando con otros agentes. En Berlín se han registrado 40 iniciativas de cesión temporal en 2007, para usos recreativos, culturales o paisajísticos y de jardinería, especialmente en suelos públicos. (Senatsverwaltung für Stadtentwicklung, 2007.)

Estos acuerdos no modifican el uso legal del suelo si los usos temporales están en contradicción con las determinaciones del planeamiento se pueden utilizar distintas medidas como la exención de requerimientos del B-Plan (Befreiung von den Festsetzungen des Bebauungsplans), que permite usos temporales distintos al definido por el plan, siempre que no se cambien sus determinaciones básicas y que el cambio sea compatible con el interés público. Según el Código de Construcción Federal, también se puede dar un permiso temporal de uso (Baurecht auf Zeit), que permite por cierto tiempo, o hasta que se den determinadas circunstancias, un uso distinto al definido por el B-Plan (BGBI, 2004).

\subsection{Reino Unido, Inglaterra, Londres}

\subsubsection{Contexto de los huertos tradicionales}

El nacimiento de los allotments en Inglaterra está marcado por la época de pobreza rural que provoca el final de los cercamientos de las tierras comunales a mediados del siglo XIX. Se piensan como medida paliativa que posibilitara el abastecimiento alimentario de los trabajadores sin recursos mediante el cultivo de pequeñas parcelas. Posteriormente su función evoluciona y jugarán un papel clave en el abastecimiento urbano durante las guerras mundiales, mediante el desarrollo de campañas como Dig For the Victory, donde se pusieron en cultivo todos los espacios libres disponibles ${ }^{16}$ (Morán y Hernández, 2011b). Los allotments han mantenido durante más de un siglo una fuerte tradición asociativa, consolidando en las ciudades reductos de una socialidad campesina (cierta autosuficiencia económica, trabajo comunitario, estrecha relación con la tierra y la alimentación...) (Crouch y Ward, 2003).
13 http://www.berlin.deutschlandsummt.de

14 http://www.anstiftung-ertomis.de/ berlin

15 http://social-seeds.net

16 Desde 2008 hay un museo conmemorativo de la campaña en St James's Park, donde se recrea dicho acontecimiento, con un huerto que es mantenido por grupos comunitarios del barrio, donde se realizan visitas escolares y actividades relacionadas con la alimentación sana y la sostenibilidad urbana. 
Figura 3. Espacios productivos en la red verde de Londres. Allotments y CG en rojo oscuro. Fuente: GLA, 2012
Los terrenos en los que se emplazan los allotments son de propiedad municipal; la autoridad local mantiene las instalaciones y alquila las parcelas mediante contrato a individuos particulares o asociaciones que se encargan de la gestión. La renta se sitúa entre las 50 y 60 libras anuales. Las asociaciones locales se federan por distrito, y se unen en una red metropolitana, la London Allotments Network. También forman parte de la National Society of Allotment and Leisure Gardeners-NSALG, que actúa como entidad consultiva frente al Gobierno central, además de ofrecer asesoramiento técnico y legal a sus socios y editar una revista (Morán y Hernández, 2011).

El último inventario detallado de allotments se realizó en 1997. En Londres la encuesta identificó unas 36.000 parcelas de huerto, agrupadas en 769 allotments, que ocupaban 111 ha; existía una lista de espera de 1.330 personas. El mayor número de allotments se encuentra en los municipios periféricos, aunque existen allotments en 29 de los 32 municipios del Gran Londres (GLA, 2006).

\subsubsection{Regulación urbanística de los huertos tradicionales}

Legislación. En Inglaterra y Gales la legislación vigente incluye determinaciones en vigor de sucesivas leyes sobre allotments, desde la de 1908 a la de 1950 (Reino Unido, 1950), que se han visto alteradas por otras, como las que regulan las competencias de los Gobiernos locales.

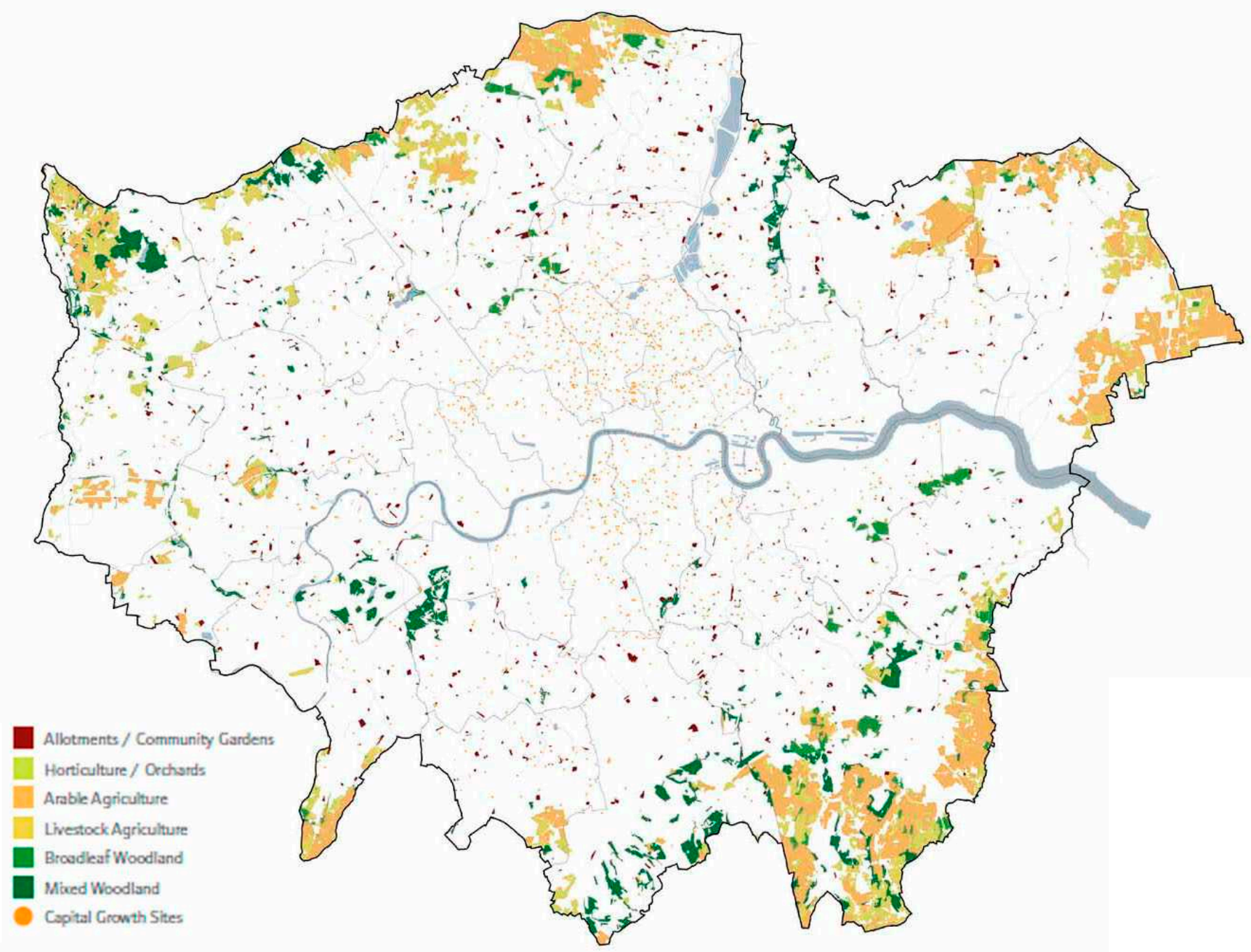


Lo más característico de la legislación se refiere a la provisión de allotments, ya que las autoridades locales están obligadas a proporcionar parcelas a la población que lo solicite (un mínimo de seis personas residentes que paguen impuestos en el lugar) y tienen el poder de expropiación de terrenos para ese fin. Las enmiendas de 1950 limitan la obligatoriedad de provisión de allotments, restringiéndola a las poblaciones de más de 10.000 habitantes, aunque esta regla no se aplica en Londres debido a la London Government Act (1963). Pese a que la ley de 1925 especificaba que en el proceso de planeamiento municipal las autoridades locales debían reservar terreno para allotments, la Town and Country Planning Act de 1947 deroga esa determinación.

Planeamiento urbano y normativa sobre usos del suelo. En Londres el planeamiento marco es el London Plan, the Spatial Development Strategy for London (GLA, 2009). Los distritos redactan el planeamiento de desarrollo, Local Development Frame-LDF (marco de desarrollo local), que debe ser aprobado por el Gobierno de la ciudad. El distrito de Hackney, por ejemplo, ha aprobado su LDF (London Borough of Hackney, 2010), incluyendo los allotments, community gardens y urban farms en su red de espacios libres, bajo la categoría de "otros espacios verdes".

El alcalde redacta documentos guía para los planes de desarrollo, como la Green Infrastructure and Open Environments: the all London Green Grid (GLA; 2012), cuyo fin es crear una red de infraestructura verde multifuncional para mejorar la calidad de vida, en la que incluye la AU. En esta guía se indica que una de las funciones de la red es "promover la producción sostenible de alimentos", se considera terreno productivo los allotments, community gardens y las granjas del borde urbano, cuya localización se puede ver en la Figura 3. Según el London Plan los distritos deben resolver las deficiencias en calidad, cantidad y accesibilidad a espacios libres, por lo que se les recomienda desarrollar sus Open Space Strategies locales.

Desde el Gobierno de la ciudad se incide en la importancia de asegurar un sistema alimentario local sostenible, el documento Mayor's London Food Strategy: Healthy and Sustaible Food for London (London Development Agency, 2006), desarrolla un plan de acción que cubre todo el sistema alimentario (producción, procesamiento, transporte, venta, preparación, almacenamiento y residuos). Una de las acciones que propone es aumentar el número de allotments y CG.

Un resumen de las determinaciones normativas de la legislación y el planeamiento para los huertos urbanos se puede ver en el Cuadro 3.

\subsubsection{Contexto de los huertos comunitarios}

Inglaterra es la principal puerta de entrada a Europa del movimiento social de los huertos comunitarios, replicando la iniciativa estadounidense. Una de sus singularidades es el fuerte impulso que reciben simultáneamente las granjas urbanas, inspiradas en los programas educativos de granjas infantiles holandesas que, además de cultivar vegetales y hortalizas, desarrollan la cría de animales y ganado en espacios urbanos. La primera granja urbana se establecía en 1972 en Kentish Town, en el distrito londinense de Camden, en un espacio junto a unas vías del tren que se convierte en una granja en la que ordeñar vacas, alimentar cerdos u ovejas, dar paseos a caballo o cuidar un huerto. Este espacio tiene el valor de ser el referente en el que se inspiraron otras iniciativas. En la actualidad existen en Londres 16 granjas urbanas y unos 100 huertos comunitarios, agrupados en la Federation of City Farms 


\begin{tabular}{|c|c|}
\hline DEFINICIÓN & $\begin{array}{l}\text { Allotment garden: parcela de no más de } 40 \text { poles }\left(500 \mathrm{~m}^{2}\right) \text {, cultivada total o principalmente con } \\
\text { verdura y fruta para el consumo personal (1922), o cualquier parcela de no más de } 5 \text { acres ( } 2 \text { ha) } \\
\text { cultivada como huerto o granja, o ambos (ańadido 1925). (Legislación) }\end{array}$ \\
\hline $\begin{array}{l}\text { USOS DEL } \\
\text { SUELO }\end{array}$ & $\begin{array}{l}\text { Bajo categoría "otros espacios verdes" - allotments, huertos comunitarios ygranjas urbanas } \\
\text { (Planeamiento de desarrollo) }\end{array}$ \\
\hline \multirow{6}{*}{$\begin{array}{l}\text { CONDICIONES } \\
\text { ACTIVIDAD }\end{array}$} & CONSTRUCCIONES: Las necesarias para la cría de animales. (Legislación) \\
\hline & $\begin{array}{l}\text { CRÍA DE ANIMALES: Aves de corral y conejos, sin que se puedan destinar a la venta, y siem pre } \\
\text { que no supongan molestias o perjuicios para la salud. (Legislación) }\end{array}$ \\
\hline & VENTADE LA PRODUCCIÓN: No se permite (Legislación) \\
\hline & $\begin{array}{l}\text { INFRAESTRUCTURAS: La autoridad local parcela el terreno, lo valla y dota de infraestructuras. } \\
\text { (Legislación) }\end{array}$ \\
\hline & $\begin{array}{l}\text { ALQUILER: La renta debe ser la "que razonablemente sea esperable que pague un inquilino por } \\
\text { este uso". El Gobierno local alquila terrenos públicos a particulares, a grupos cooperativos, o a } \\
\text { asociaciones creadas a este propósito. (Legislación) }\end{array}$ \\
\hline & $\begin{array}{l}\text { FIN DEL CONTRATO E INDEMNIZACIÓN: Cuando los terrenos no se consideren necesarios o } \\
\text { existan otros más adecuados el municipio los podrá vender o alquilar para otras actividades, con } \\
\text { la aprobación de un comité de evaluación, y aprobación ministerial (Minister of Agriculture and } \\
\text { Fisheries o el Secretary of State). El municipio debe as egurar el realojo y pagar compensaciones } \\
\text { por desalojo, vinculadas a la estación yal valor de la cosecha. (Legislación) }\end{array}$ \\
\hline
\end{tabular}

Cuadro 3. Regulación de los huertos tradicionales según legislación y planeamiento. Fuente: elaboración propia.
17 Ver http://www.farmgarden.org.uk/ farms-gardens/your-region/london

18 Para una vista general de instituciones que trabajan AU ver (Morán, 2008), (Verdaguer, 2010).

19 Ver http://www.capitalgrowth.org/ y http://www.capitalgrowth.org/bees/

20 http://www.openfields.org.uk/topics/social-and-community-enterprise/ community-garden-starter-pack.html and Community Gardens $;{ }^{17}$ tienen funciones educativas (visitas escolares, campamentos de verano), productivas (cooperativas de alimentos) y recreativas (juegos infantiles y deportes al aire libre), colaborando con colegios y Administraciones municipales.

La horticultura comunitaria se ha popularizado y actualmente son numerosos los agentes que la fomentan desde el impulso de sistemas alimentarios locales. Una iniciativa destacable por su colaboración entre la Administración pública y los colectivos sociales sería el programa Capital Growth. London 2012, con subvención de la GLA (Greater London Authority), para la creación de 2.012 nuevas áreas de cultivo urbano en la ciudad antes de las Olimpiadas, tanto en terrenos públicos como privados, admitiendo también proyectos comerciales. El objetivo se consiguió con la colaboración de diversas organizaciones que cedieron parcelas, materiales o apoyo técnico, como la National Trust, la Royal Horticultural Society, Sustain, Big Lottery's Local Food Fund... ${ }^{18}$ En la Figura 4 se puede observar el mapa oficial en el que se localizan todos los proyectos; el mantenimiento de muchos de ellos se realiza mediante el programa de voluntariado municipal Harvest Mob Volunteers. Además, disponen de un programa de formación con sede en Regent's Park, tienen publicaciones específicas e impulsan la creación de grupos de consumo de productos locales y ecológicos. En 2011 la campaña fue ampliada con Capital Bee ${ }^{19}$ para fomentar la apicultura y acabar con el uso de pesticidas en la ciudad; participan 50 grupos comunitarios en colegios, universidades, empresas y parques.

\subsubsection{Regulación de los huertos comunitarios}

Su situación legal no es tan estable como la de los allotments pero con el paso de los años se ha generado una suerte de reconocimiento institucional. La Federation of City Farms and Community Gardens dispone de un protocolo ${ }^{20}$ para organizar la selección de parcelas y establecer 


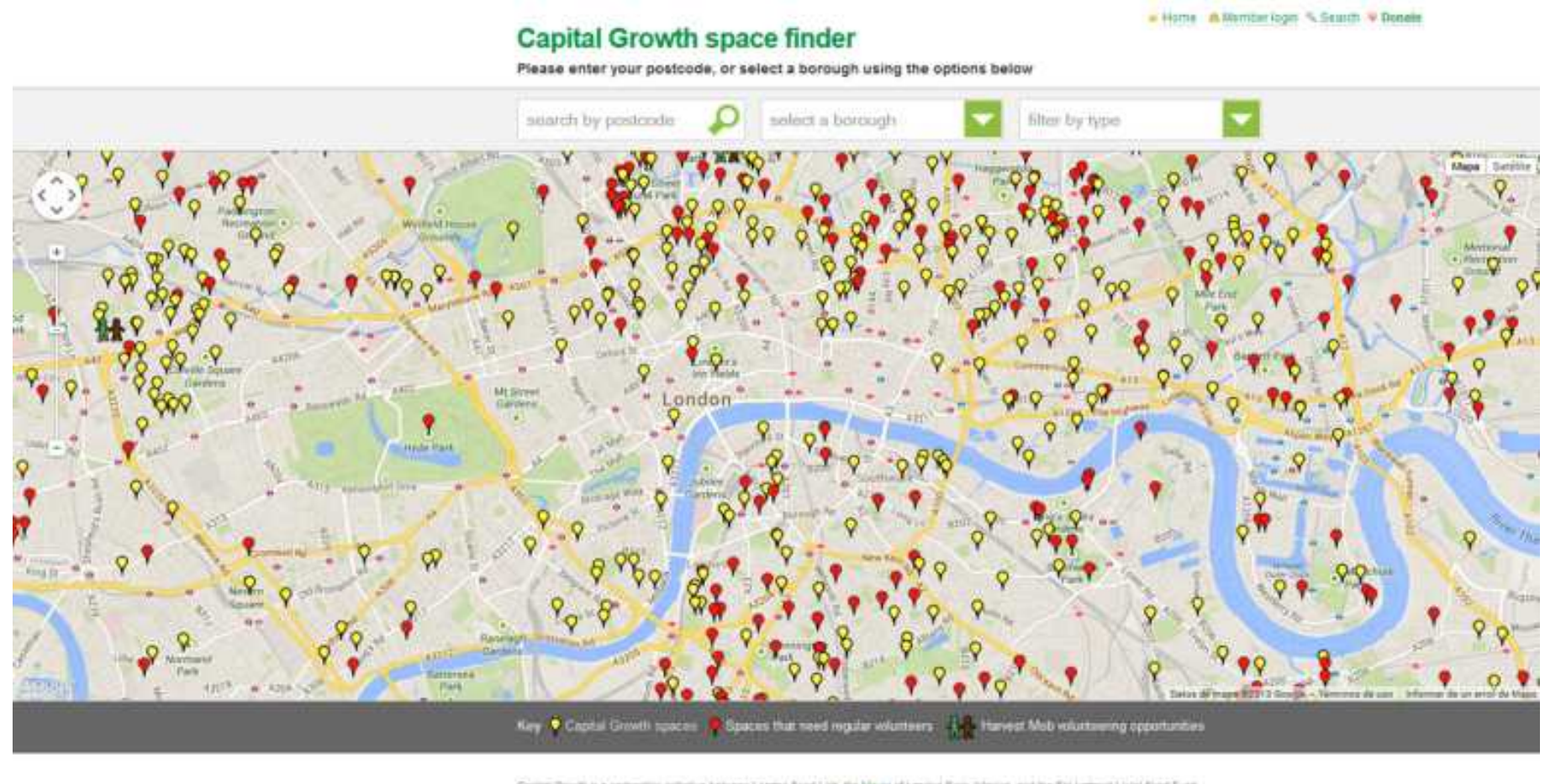

MAYOR OF LONDON

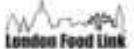

negociaciones con las Administraciones locales. Los huertos comunitarios que se han ido regularizando acceden a cesiones temporales de uso o a alquileres simbólicos de terrenos municipales o privados, a través de la mediación institucional. La diversidad de suelos que acogen estos proyectos va desde áreas de allotment, a terrenos de hospitales, asociaciones, parques, cementerios y antiguas iglesias, colegios, tierras agrícolas periurbanas o solares urbanos en desuso.

\subsection{Estado español}

Ante la escasez y falta de desarrollo de legislación y normativas, más que presentar un estudio de caso describiremos los modelos y desarrollos normativos más significativos de nuestras ciudades.

\subsubsection{Contexto de los huertos tradicionales}

La agricultura urbana es una realidad muy reciente en el caso español, tras una oleada masiva de ocupaciones de parcelas públicas en la periferia de las grandes metrópolis durante la crisis económica de los ochenta, se ponen en marcha las primeras políticas públicas de huertos de ocio (Gaviria y Baigorri, 1985). La pionera se inaugura en San Fernando de Henares (Madrid) en 1988, con 250 parcelas para agricultura ecológica de autoconsumo, educación ambiental y ocio, concibiendo las instalaciones como un espacio de encuentro.

Un modelo que sería la referencia para iniciativas posteriores, como la de Barcelona que en 1996, mediante un programa del área de Medio Ambiente del Ayuntamiento, conformará una Red de Huertos Urbanos dirigida específicamente a personas de más de 65 años, aunque algunas parcelas se ceden a personas en exclusión social y a colegios. El tamaño de las parcelas va de los 25 a los $40 \mathrm{~m}^{2}$, se asignan por sorteo, durante un tiempo no superior a cinco años. Existen zonas de granja y colmenas en las parcelas gestionadas por la Administración, pero no
Figura 4. Buscador de espacios de cultivo de la campaña. Fuente: web de Capital Growth [Consultada en septiembre de 2013] 
en las individuales. Similar es el caso de Vitoria con las Huertas de Olarizu y las de Urarte. Las primeras están dirigidas a personas mayores de 55 años no activas profesionalmente, que tras un curso optan a la cesión de una de las parcelas por sorteo, por una duración de un año prorrogable hasta tres. En Urarte cualquier persona mayor de edad puede acceder a las parcelas individuales, además hay otras para proyectos educativos, terapéuticos o de investigación.

Estos modelos centralizados contrastan con la experiencia sevillana impulsada por el movimiento vecinal desde los años ochenta. Tras la ocupación de una parcela (parque urbano según el planeamiento), la asociación Comité Pro-Parque Miraflores impulsa la autoconstrucción de una zona de huertos, dinamiza el proyecto, la gestión de las parcelas y la intermediación con el Ayuntamiento que regulariza la iniciativa en 1996. Para participar no hay criterios de acceso, la permanencia es indefinida, la producción se orienta al autoconsumo y se maneja siguiendo los principios de la agricultura ecológica. La asociación recibe algunas subvenciones y dispone de un amplio apoyo vecinal, tanto de las entidades ciudadanas, como de la población no asociada. Este modelo de base asociativa es el seguido por el municipio par el tratamiento de otros espacios de AU (Puente, 2012).

\subsubsection{Regulación de los huertos tradicionales}

Legislación. No existe legislación estatal o autonómica relativa a la AU.

Planeamiento urbano y normativa sobre usos del suelo. En el planeamiento general de los municipios del Estado español no hay referencias a la AU. No existe definición de este uso, calificación de suelo urbano específica, ni se incluye como uso permitido en otras calificaciones. Aunque no hay un criterio común, normalmente los huertos municipales se sitúan en zonas verdes o de equipamiento. En Vitoria están dentro del Anillo Verde, en un parque periurbano clasificado como suelo "No urbanizable agrícola paisajístico"; en Barcelona la mayor parte de los huertos del programa municipal se localizan en suelo urbano calificado como "Parques y Jardines" (5 de 12), los restantes se sitúan en suelos calificados como "Equipamientos", "Parque Forestal" o "Verde privado protegido". ${ }^{21}$ En Sevilla también se encuentran en zonas verdes.

\subsubsection{Contexto de los huertos comunitarios}

Los huertos comunitarios se han impulsado durante la última década y especialmente durante los últimos años. Asociaciones vecinales o ecologistas recuperan solares y espacios públicos persiguiendo objetivos sociales, educativos y ambientales. Iniciativas que han crecido de forma exponencial con el desarrollo de la crisis (Fernández Casadevante y Morán, 2012). La situación predominante es de alegalidad, el caso de la Red de Huertos de Madrid es paradigmático al ser una Buena Práctica en sostenibilidad urbana reconocida por el Programa Hábitat de NNUU y por el Ministerio de Fomento, a pesar de tener el $80 \%$ de

21 Buscador de ámbitos de planeamiento del Plan General Metropolitano de Barcelona. [Consultada en mayo de 2013. http://w110.bcn.cat/portal/site/Urbanisme/menuitem.38ead442d60e56329fc5 9fc5a2ef8a0c/?vgnextoid=3edf408f99e 48 210VgnVCM10000074fea8c0RCRD\&lang =es_ES. sus huertos en situación de alegalidad.

\subsubsection{Regulación de los huertos comunitarios}

En casos excepcionales, los huertos comunitarios han obtenido una cesión temporal de suelos públicos, pero lo más habitual es que se en- 
cuentren en una situación alegal. Muchos grupos han entablado conversaciones con los Ayuntamientos con el fin de generar un marco normativo que permita regular este tipo de actividades y las consolide en la ciudad.

En Madrid el proyecto "Ésta es una plaza" es un ejemplo de espacio regulado mediante una cesión temporal gratuita (de no más de cinco años). Se trata de un suelo de equipamiento que el Área de Gobierno de Urbanismo y Vivienda del Ayuntamiento de Madrid cede a la asociación. Ésta debe vallar el solar y afrontar el pago de cualquier obra de mejora o acondicionamiento, y ocuparse de la solicitud de "licencias, autorizaciones y permisos de cualquier tipo, incluidos los de agua y luz" (Ayuntamiento de Madrid, 2009). Como muchas de estas licencias no son competencia del Área de Gobierno que cede el suelo (por ejemplo, la instalación de agua) y ésta tampoco ejerce de intermediaria, las trabas burocráticas dificultan el desarrollo de los proyectos.

Barcelona ha lanzado recientemente el Pla BUITS (Buits Urbans amb Implicació Territorial $i$ Social), para la activación de espacios públicos vacíos, en el que dos parcelas de cada distrito se ceden temporalmente (un año prorrogable hasta tres) a entidades para desarrollar iniciativas sociales que dinamicen el entorno y el tejido social. Las condiciones de cesión son similares a las de Madrid, aunque se enmarquen en un plan más ambicioso. Las entidades son responsables de las obras de acondicionamiento y la instalación de servicios, que se exige que sean las mínimas posibles; cabe la posibilidad de solicitar apoyo económico del Ayuntamiento, pero en el concurso de adjudicación se obtienen más puntos si no se hace. Se admiten actividades secundarias que generen rendimientos económicos, si son para autofinanciación. A petición del Ayuntamiento o a la finalización del tiempo de cesión se deben devolver los terrenos y desmontar las instalaciones, sin derecho a indemnización. De las 19 iniciativas concedidas 8 son proyectos de huertos urbanos comunitarios. ${ }^{22}$

Hasta la fecha el modelo más ambicioso es el impulsado por el Ayuntamiento barcelonés de Terrasa, ${ }^{23}$ que ha elaborado un censo de solares (públicos y privados) y una normativa para que asociaciones del municipio puedan acceder a su gestión y cultivo de forma temporal. Una suerte de aplicación de las ideas de la custodia del territorio a los entornos urbanos, donde el Ayuntamiento media, da facilidades y proporciona incluso el agua necesaria.

\section{Conclusiones}

Ocurre con las ciudades lo que en los sueños: Todo lo imaginable puede ser soñado, pero hasta el sueño más inesperado es un acertijo que esconde un deseo, o más bien su inversa, un temor. Las ciudades, como los sueños, están construidas de deseos y temores, aunque el hilo de su discurrir sea secreto, sus normas absurdas, sus perspectivas engañosas y cada cosa esconda otra. Italo Calvino

Los huertos que hemos llamado tradicionales son una tipología propiamente europea, su origen y avatares históricos hacen que formen parte de la cultura popular. La lección que podemos obtener de ellos
22 http://w110.bcn.cat/portal/site/HabitatUrba/menuitem.7014095af2202d613 d303d30a2ef8a0c/?vgnextoid=4f0cc9152 d1a7310VgnVCM10000072fea8c0RCRD\& appInstanceName=default\&lang=ca_ES 23 http://www.mediambient.terra ssa.cat/index_not.asp?na $=0 \&$ ns $=1 \& \mathrm{cnl}=$ $2 \& \mathrm{np}=1 \& \mathrm{nt}=10$. 
es el éxito de la gestión comunitaria de espacios públicos, con una separación de obligaciones y responsabilidades entre Administración y asociaciones, y la participación de éstas en órganos de planificación urbana. Parece una conclusión obvia, pero observando las prácticas habituales en nuestra geografía no está de más recalcarla.

En cuanto a los huertos comunitarios, los norteamericanos son los pioneros, y han servido de inspiración a proyectos similares en Europa. En EE. UU. la AU está adquiriendo un nuevo momento de auge a raíz de la crisis urbana y alimentaria que se acentúa en barrios y ciudades de menos recursos; en este sentido, la dimensión productiva es fundamental, con fines alimentarios y de creación de empleo. Los huertos comunitarios europeos (incluidos los nuestros) siguen la estela del ejemplo americano, aunque de momento son entendidos más como espacios con funciones sociales, educativas o políticas. También se están desarrollando incipientemente tipologías comerciales (cooperativas, empresas sociales...). Quizás la diferencia fundamental de los huertos comunitarios de nuestro país es su relativa "soledad", al margen ya del apoyo administrativo, tampoco hay alianzas similares a las americanas o europeas, en las que participan variados agentes: universidades, fundaciones, asociaciones, sindicatos... Esto puede deberse a su relativa juventud como espacios de movilización política y de propuesta de alternativas al modelo urbano y económico.

En cuanto a los marcos normativos, en el Cuadro 4 se pueden comparar las determinaciones y su grado de obligatoriedad en los distintos casos. La existencia de legislación en los europeos se remonta a la misma aparición de los espacios de AU, a comienzos del siglo XX, sin cambios significativos en nuestros días. Las leyes definen el objeto y regulan las condiciones de uso y de desalojo, lo que ha permitido la permanencia de la actividad incluso en periodos de poco interés por ella. En contraste, la legislación sobre AU en EE. UU. es nueva, y está surgiendo en la actualidad como respuesta a los obstáculos que encuentra un movimiento consolidado y creciente, que ha sido capaz de obligar a la reformulación de políticas y marcos normativos. De este modo, los Estados han reconocido la importancia de la AU, hasta el punto de legalizarla e incluso fomentarla.

El papel que se le da a la AU en el modelo urbano en los casos estudiados es recreativo, de contacto con la naturaleza y en menor medida de ecología urbana, como parte del sistema verde. Son muy interesantes las referencias, innovadoras desde el urbanismo, a los sistemas locales de alimentación, y a la reserva de suelo para el abastecimiento de alimentos de calidad.

El reconocimiento de la AU en la planificación urbanística permite localizar espacialmente la actividad, asegurando su permanencia al menos durante el periodo de vigencia del plan. Esto refuerza su papel dentro del sistema urbano, valorizando los espacios en sí, no como usos que pueden ser relocalizados sin consecuencias (peligro que han corrido los huertos tradicionales europeos). En todos los casos analizados (excepto los del Estado español) la AU es un uso de suelo admisible, con calificación o categoría propia, o en su defecto definido como uso permitido en otras categorías de suelo. Las condiciones que se exigen a la actividad (construcciones, animales, venta...) son variadas y dependen de las peculiaridades locales, los huertos comunitarios son mucho más flexibles a la hora de acoger distintos usos, aunque como hemos visto también son más vulnerables al carecer de una regulación concreta (excepto en EE. UU.). En cualquier caso, la revisión de estas 
determinaciones nos permite advertir que opciones que ni siquiera se plantean aún en nuestro país, como la apicultura urbana, o la cría de animales, son comunes en otras latitudes. Uno de los principales problemas que afrontamos es que ningún Ayuntamiento se decide a dar el paso de modificar el planeamiento aprobado o de replantear las premisas sobre las que tradicionalmente se ha redactado, manteniendo los proyectos de AU en la alegalidad o regulándolos mediante herramientas excepcionales y no replicables ni generalizables.

Las herramientas de cesión temporal pueden utilizarse como soluciones a corto plazo, pero no suponen un marco estable para el desarrollo de la AU. Es la solución utilizada en momentos de crisis inmobiliaria dado que es fácil revocarlos cuando se produce un cambio coyuntural, y adolece de los peligros que destaca Rosol (2010): desregulación, desentendimiento institucional en el cumplimiento de sus obligaciones y responsabilización de la población. Este tipo de soluciones presenta problemas precisamente por la temporalidad, en Alemania el momento de finalización de un permiso temporal suele provocar la oposición y resistencia de los promotores del proyecto (Blummer, 2006). Los ejemplos de cesiones en precario de Madrid y Barcelona frente a los modelos de otras ciudades resultan ciertamente insuficientes, en Estados Unidos se exige un mínimo de cinco-diez años de cesión para asegurar la viabilidad de los huertos, en nuestro país el tiempo máximo se establece en tres o cinco años, a esto hay que añadir la inexistencia de apoyo económico o de otras medidas de coordinación y apoyo.

Los programas municipales fuera de nuestro país son espacios de relación entre Administración local y grupos comunitarios, coordinan la acción de las distintas áreas municipales y actúan como paraguas para la colaboración de otros agentes que apoyan las iniciativas técnica o materialmente. Esto no es así en el caso español, donde los programas municipales siguen un modelo muy centralizado, sin espacio para la gestión comunitaria.

Este recorrido por la AU en ciudades occidentales muestra su posición estratégica en la agenda política, y el variado repertorio de medidas y herramientas que se están desarrollando en otros países. Aunque su traslación a nuestras ciudades no puede ser directa debido a las peculiaridades morfológicas y funcionales de la ciudad mediterránea, queda claro que las políticas de AU deben ser más ambiciosas e insertarse en la agenda ambiental, económica y urbanística.

El momento actual de crisis presenta una oportunidad de desarrollo para la AU, debido a la paralización del desarrollo de suelos en las periferias urbanas, y la dificultad de construcción de equipamientos públicos y de mantenimiento de espacios verdes en el centro de la ciudad. Según la densidad de urbanización y las características de los espacios libres disponibles, se podrían establecer diversas tipologías de AU. Desde granjas y huertos productivos, demostrativos y experimentales en los grandes vacíos periurbanos, conformando anillos y cuñas agrícolas en las que se podrían desarrollar proyectos agroecológicos a gran escala (cierre de ciclos, reproducción de variedades locales...) hasta huertos de ocio municipales, huertos escolares y de otras instituciones, y huertos comunitarios de vecindario en los vacíos urbanos del interior de la ciudad, como espacios de proximidad con funciones de ocio y educación principalmente.

Una ley específica sobre agricultura urbana podría definir la variedad de funciones y tipologías, estableciendo los criterios y condiciones 
para la designación y protección de espacios, delimitando las responsabilidades de la administración pública, así como los derechos y obligaciones de asociaciones y hortelan@s.

Resultaría necesaria también la modificación de las leyes del suelo autonómicas y como consecuencia el planeamiento urbanístico, que debería incluir una nueva "Red de zonas verdes y espacios libres agrícolas", estableciendo estándares de cantidad, calidad y distancia para las redes local y general, así como regulando los usos y condiciones de seguridad en cada uno de ellos (si se permite o no la cría de animales, uso comercial o no...). Esta nueva red supondría un gran avance en el modo de pensar la ciudad, reconociendo la producción de alimentos como necesidad social y como uso estructurante del modelo territorial y urbano. Requeriría la definición de funciones, usos y modos de gestión específicos para los distintos niveles jerárquicos de la red: red supramunicipal de valor estratégico que proteja los sistemas productivos a escala regional, red general que asegure un determinado grado de abastecimiento alimentario a la ciudad y red local a escala de barrio. La integración de la AU en el modelo urbano desde el concepto de red permitiría superar conflictos y presiones por el uso del suelo, clarificando la complementariedad y la relación entre los distintos espacios desde el centro urbano hasta las áreas rurales.

Centrándonos de nuevo en los huertos urbanos, como medida transitoria, pero a nuestro modo de ver insuficiente, se puede incorporar al planeamiento la permisión de usos temporales en los suelos públicos sin desarrollar. En cualquier caso, no es admisible la cesión de suelo sin responsabilizarse de que cuente con las condiciones y recursos necesarios, sin coordinación entre áreas municipales o sin un mínimo apoyo administrativo, económico o técnico. El desarrollo de programas municipales de AU sería el marco de actuación idóneo para la coordinación de los distintos agentes públicos a escala autonómica y municipal (consejerías y concejalías, empresas públicas, universidades...) y sociales (fundaciones, asociaciones, grupos comunitarios, AMPA...), como espacio en el que organizar los recursos y servicios para el fomento de la AU: suelo, infraestructuras, semillas, herramientas, conocimiento, etc. De modo que se facilitase la identificación de espacios disponibles; se desarrollasen protocolos de asignación de suelos asegurando las condiciones necesarias; y se estableciesen alianzas para llevar a cabo campañas de divulgación y proyectos formativos, ambientales, educativos, etc.

Finalmente, consideramos necesario que se establezcan los medios para la participación en los espacios de decisión de los protagonistas directos de la AU, los hortelanos y las hortelanas, agrupados en asociaciones y redes. El proyecto urbano que subyace en los proyectos que desarrollan debe ser tenido en cuenta a la hora de tomar decisiones sobre la ciudad. 


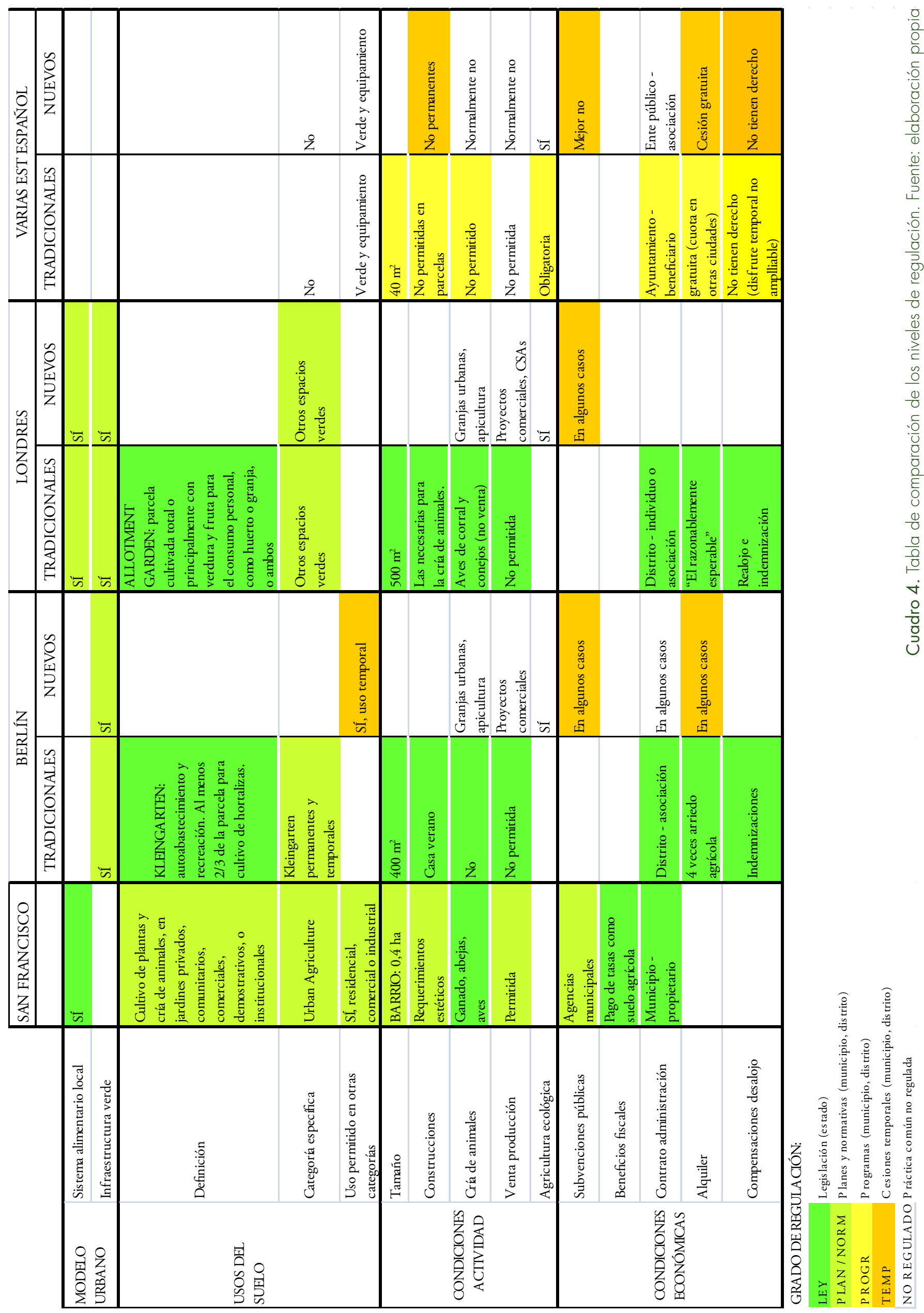


AYUNTAMIENTO DE MADRID. Expediente de autorización de ocupación. Dirección General de Gestión Urbanística, Subdirección General de Patrimonio Municipal de Suelo, Ayuntamiento de Madrid, 2009.

BGBI. Baugesetzbuch in der Fassung der Bekanntmachung. [Código de la edificación] Versión publicada el 23 de septiembre de 2004 (BGBl. I. S. 2414), modificado por el artículo 1 de la Ley de 11 de junio de 2013 (BGBI. I.S. 1548). Disponible en: <http:// www.gesetze-im-internet.de/bbaug/index.html> (Consultado el 10 de septiembre de 2014).

BGDI. Bundeskleingartengesetz (BkleingG). [Ley Federal de adjudicación de kleingarten] Versión publicada el 28 de febrero de 1983 (BGBl. I S. 210), modificado por el artículo 11 de la Ley de 19 de septiembre de 2006 (BGBI. I.S. 2146). Disponible en: <http:/ / www.gesetze-im-internet.de/bkleingg/ BJNR002100983.html> (Consultado el 10 de septiembre de 2014).

BLUMMER, Nicole. Planning for the Unplanned: Tools and Techniques for Interim Use in Germany and the United States. Occasional Papers collection, 2006, Deutches Institut für Urbanistik, German Institute of Urban Affairs, Berlin. Disponible en: <http://www.difu.de/system/files/archiv/publikationen/reihen/occasional-papers/06-blumner_ planning.pdf> (Consultado el 10 de septiembre de 2014).

CITY AND COUNCIL OF SAN FRANCISCO. Urban Agriculture Ordinance. Chapter 53, Sections 53.1 - 53.4, San Francisco Administrative Code. Oct. 2012. Disponible en: <http://sfgsa.org/modules/showdocument.aspx?documentid=9202> (Consultado el 10 de septiembre de 2014)

CITY OF SAN FRANCISCO. Urban Agriculture Strategic Plan. City of San Francisco, 2013.

CITY OF PORTLAND. Urban Food Zoning Code Update. Bureau of Planning and Sustainability, City of Portland. Adopted effective: June 13, 2012. Disponible en: <www.portlandonline.com/bps> (Consultado el 10 de septiembre de 2014).

CROUCH, David y WARD, Colin. The Allotment: Its Landscape and Culture. London: Five leaves publications, 2003.

FERNÁNDEZ CASADEVANTE José Luis. La ciudad de Detroit como metáfora: colapso, transición y agricultura urbana. Revista Ecologista, 2012, n. ${ }^{\circ}$ 75. Disponible en: <http://www.ecologistasenaccion.org/ article25318.html> (Consultado el 10 de septiembre de 2014).

GAVIRIA, Mario y BAIGORRI, Artemio. Agricultura periurbana. Madrid: Ed. Consejería de Ordenación del Territorio, Medio Ambiente y Vivienda, 1985.
GLA. Green Infrastructure and Open Environments: the all London Green Grid. London: Greater London Authority-GLA, 2012.

GLA. London Plan, the Spatial Development Strategy for London. London: Greater London Authority-GLA, 2009.

GLA. A Lot to Lose: London's disappearing allotments. London: Greater London Authority - GLA, October 2006.

GOLDSTEIN, Mindy et al. Urban Agriculture. A Sixteen City Survey Of Urban Agriculture Practices Across The Country. Turner Environmental Law Clinic, Emory Law School, 2011.

LAWSON, Laura. Bountiful city. A century of community gardening in America. Paperback. California University, 2005.

LONDON DEVELOPMENT AGENCY. Mayor's London Food Strategy: Healthy and Sustainable Food for London. London Development Agency, 2006.

LONDON BOROUGH OF HACKNEY. Local Development Framework. Core Strategy. Hackney's strategic planning policies for 2010-2015. Adopted novembre 2010. London Borough of Hackney, 2010.

MORÁN, Nerea. Huertos urbanos en tres ciudades europeas. Londres, Berlín y Madrid. Biblioteca Ciudades por un Futuro Más Sostenible, 2009. Disponible en: <http:/ / habitat.aq.upm.es/boletin/n47/anmor. html> (Consultado el 10 de septiembre de 2014)

MORÁN, Nerea y HERNÁNDEZ AJA, Agustín. Regulación, participación y agricultura urbana. Análisis legislativo, normativo y de modelos de gestión en Londres, Berlín y Madrid. I Congreso Estatal de Agricultura Ecológica Urbana y Periurbana, Elche, 2011.

MORÁN, Nerea y HERNÁNDEZ AJA, Agustín. Historia de los huertos urbanos. De los huertos para pobres a los programas de agricultura urbana ecológica. I Congreso Estatal de Agricultura Ecológica Urbana y Periurbana, Elche, 2011.

PUENTE ASUERO, Raúl. Los huertos urbanos de Sevilla: de la tradición a la novedad. Diputación de Sevilla, Servicio de Archivo y Publicaciones, 2012.

REINO UNIDO. England and Wales Allotments Act, 1950, and the Allotments Acts, 1908 to 1931. Revised enacted UK Legislation, 1950. Disponible en: <http:/ / www.legislation.gov.uk/> (Consultado el 10 de septiembre de 2014).

ROSOL, Marit. Public participation in Post-Fordist Urban Green Space Governance: the case of community gardens in Berlin. International Journal of Urban and Regional Research, 2010, vol. 34.3, p. 548-563. DOI:10.1111/j.1468-2427.2010.00968.x.

SENAT VON BERLIN. Verwaltungsvorschriften über Kündigungsentschädigung auf Kleingartenland [Dis- 
posiciones administrativas sobre indemnizaciones por finalización kleingarten], Senat von Berlin, $11 / 02 / 2003$.

SENAT VON BERLIN. Verwaltungsvorschriften über Dauerkleingärten und Kleingärten auf landeseigenen Grundstücken [Disposiciones administrativas sobre Dauerkleingarten y kleingarten en suelos de propiedad estatal], Senat von Berlin, 15/12/2009

SENAT VON BERLIN. Verwaltungsvorschriften über die Anerkennung und Überwachung der kleingärtnerischen Gemeinnützigkeit [Disposiciones administrativas para el reconocimiento de asociaciones de kleingarten sin ánimo de lucro] Senat von Berlin, 15/09/2009.

SENATSVERWALTUNG FÜR STADTENTWICKLUNG UND UMWELT BERLIN. Strategie Stadtlandschaft Berlin. [Estrategia de paisaje urbano de Berlín] Senatsverwaltung für Stadtentwicklung und Umwelt [Departamento del Senado para Desarrollo Urbano y Medio Ambiente] Berlin, Oktober 2012.

SENATSVERWALTUNG FÜR STADTENTWIC-

KLUNG. Urban pioneers. Berlin Stadtentwicklung durch
Zwischennutzung / Temporary Use and Urban Development in Berlin. Berlin: Jovis, 2007.

STATE OF CALIFORNIA. Urban Agriculture Incentive Zones Act. State of California, 2013. Dispocnible en: <http:/ /leginfo.legislature.ca.gov/faces/billNavClient.xhtml?bill_id=201320140AB551> (Consultado el 30 de septiembre de 2014).

STATE OF CALIFORNIA. Food safety: cottage food operations. State of California, 2012. Disponible en: $<$ http:/ / leginfo.legislature.ca.gov/faces/billAnalysisClient.xhtml> (Consultado el 30 de septiembre de 2014).

VERDAGUER, Carlos. Planificación del desarrollo y preservación de los usos agrícolas en el Gran Londres (Gran Bretaña). En VERDAGUER, Carlos y VÁZQUEZ, Mariano (Coords.) El espacio agrícola entre el campo y la ciudad. Madrid, GIAU+S y CEA, 2010. Disponible en: <http://habitat.aq.upm.es/ eacc/alondres.html > (Consultado el 10 de septiembre de 2014).

MORÁN ALONSO, Nerea y FERNÁNDEZ

DE CASADEVANTE, José Luis. A desalambrar. Agricultura urbana, huertos comunitarios y regulación urbanística. Hábitat y Sociedad, 2014, n. ${ }^{\circ}$ 7, pp. 31-52.

$<$ www.habitatysociedad.us.es >

http://dx.doi.org/10.12795/HabitatySociedad.2014.i7.03

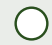

